\title{
Fundamental studies on shear-induced nucleation and beta-phase formation in the isotactic polypropylene-effect of the temperature
}

\author{
W. H. Bednarek ${ }^{1}$ D. Paukszta ${ }^{1} \cdot$ M. Szostak ${ }^{2} \cdot$ J. Szymańska ${ }^{1}$
}

Received: 22 March 2021 / Accepted: 5 July 2021 / Published online: 27 October 2021

(c) The Author(s) 2021

\begin{abstract}
The complex and incompletely understood phenomenon of shear-induced crystallization of polymers may be nowadays analysed via the in situ POM-shear stage methodology. In this research, the two main issues were investigated with the use of the Linkam CCS450 shear stage connected with POM microscope. It was found that the secondary nucleation in the tree well-known temperature regimes plays the greater role in the overall crystallization kinetics than the shear induced primary nucleation. Furthermore, it was found that the tendency towards $\beta$-phase formation in shear conditions is dependent on the temperature value during shear treatment. It may be concluded that the temperature is the key parameter in the primary and secondary nucleation process and beta-phase formation in the iPP melts.
\end{abstract}

Keywords Isotactic polypropylene $\cdot$ Shear-induced crystallization $\cdot$ Supermolecular structure $\cdot$ Spherulites formation

\section{Introduction}

Since its discovery, the isotactic polypropylene (iPP) has been found to have many applications in various areas in view of its satisfactory properties and relative low material cost [1-3]. The discovery of stereospecific olefins polymerization catalysts enabled the efficient iPP synthesis on the industrial scale and its widespread use in man-made material technology, especially in the production of composites [4-16].

The observations of formation of different crystalline morphologies (e.g., spherulites or fibrils) were carried out as well as the crystallization kinetics (e.g., the issue of crystallization regimes) [17]. The last one is based on the Hoffman-Lauritzen theory and includes the dependence between the crystallites growth rate $(\mathrm{G})$ and several factors, which are presented in Fig. 1. It can be defined by two different steps of nucleation: deposition of a critical nucleus

D. Paukszta

Dominik.Paukszta@put.poznan.pl

1 Institute of Chemical Technology and Engineering, Faculty of Chemical Technology, Poznan University of Technology, Berdychowo 4, 60965 Poznan, Poland

2 Institute of Materials Technology, Faculty of Mechanical Engineering, Poznan University of Technology, Poznan, Poland (i) and later the deposition of stems adjacent to nuclei (g) $[18,19]$. The secondary nucleation process may occur in three different crystallization regimes: regime I - where the $\mathrm{g}>>\mathrm{i}$; regime II - where $\mathrm{g} \sim \mathrm{i}$ and regime III - where $\mathrm{g}<<\mathrm{i}$ (Fig. 1) [19, 20].

Moreover, with the use of determined crystallites growth rate $(\mathrm{G})$, it may be possible to prepare a curve, showing the values of $\mathrm{K}(\mathrm{g})$ - describing the crystallites growth-in three different regimes, where the key is the temperature value during isothermal crystallization.

It is impossible to recall the iPP without evoking the polymorphism phenomenon, it can be identified by different crystallographic forms: $\alpha, \beta$ and $\gamma$ (moreover, the smectic form) [3, 21-23]. Polymorphism in isotactic polypropylene is our long-term research topic [22, 24, 25]. The $\alpha$ form is the most commonly observed form of isotactic polypropylene. The $\gamma$ form of iPP is formed during high pressure crystallization as well as for short chain polymers. The $\beta$ form of isotactic polypropylene can be obtained by providing suitable conditions for crystallization, such as high temperature gradients, the presence of shear forces or by using appropriate nucleating agents. The value of the equilibrium melting point for the $\beta$ form is estimated to be around $150{ }^{\circ} \mathrm{C}$. During the crystallization of the $\beta$ form, it is possible to produce two types of spherulites. Subjecting to deformation above the elastic limit may convert the $\beta$ form to the $\alpha$ form of an isotactic polypropylene [3]. The 


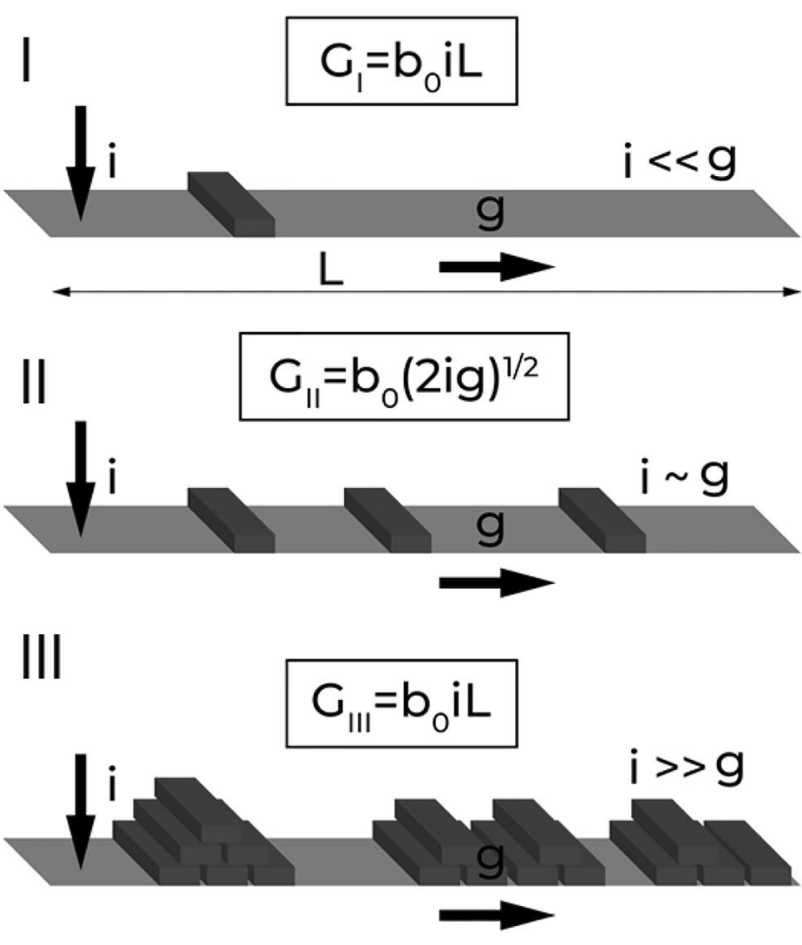

Fig. 1 The growth of crystalline structures in three different regimes

presence of the $\beta$ form in the material may result in high impact strength and low stiffness of the material. So far, the mechanism of beta form formation has not been fully elucidated.

Several factors, e.g.: the undercooling ratio [26, 27], the effect of nucleating agents [28-31] and the shear forces influence [32-34] have a strong impact on creating the supermolecular structure in iPP, especially the $\beta$-form. In the processing of polypropylene with use of the most popular techniques, e.g., extrusion or injection molding, shear forces affect the polymer. It is related to direct contact between the polymer and the walls of mold or processing nozzle and between polymer matrix and the filler particles in composites (what may be called "local shearing") [35-38].

Presently used techniques allow observation of a formation of the polymer ordered structures in situ, directly during the shear forces treatment. There have been many attempts to do the research on polypropylene [39-51] and its composites $[29,52,53]$, and also the polymer blends [54, 55] with use of Linkam CSS450, also called Oxford shear stage. Despite many results presented in the literature, the application of the Linkam system still enables one to make unique and interesting observations.

This study was focused on the polymorphism and crystallization kinetics in the iPP in case of shear induced nucleation in three different crystallization regimes by using different crystallization temperatures.

\section{Experimental}

\section{Materials}

In the current research, the commercial isotactic polypropylene Malen P S-702 (iPP) was used, with the MFR value $13.0 \mathrm{~g} / 10 \mathrm{~min}$, manufactured by Bassel Orlen Polyolefins, Poland. The iPP granules were dried in the convection dryer in the temperature $80^{\circ} \mathrm{C}$ for $12 \mathrm{~h}$. Afterwards, with use of the hydraulic press (in the temperature $230^{\circ} \mathrm{C}$ and with the 5 ton pressure), the $300 \mu \mathrm{m}$ thick iPP foils were prepared. The iPP films were used in the: structural (WAXS), thermal (DSC) and microscopic (POM) investigations.

\section{The structural and thermal investigations}

For the analysis of iPP structure in thin films, the WAXS analyze (Wide Angle X-Ray Scattering) was carried out with the use of a horizontal diffractometer $(\mathrm{CuK} \alpha$ radiation with use of nickel filtering, $\lambda=1.5418 \AA$ ). The following parameters were applied: voltage $30 \mathrm{kV}$, anodic current $25 \mathrm{~mA}$, angle range $2 \Theta: 10-30^{\circ}$, counting step $(2 \Theta)$ : $0.04^{\circ}$, counting time: $3 \mathrm{~s}$, with remaining standard parameters. Performed WAXS studies were used in determining the fundamental parameters, like: maxima intensities and amount of $\beta$-iPP in overall crystalline phase in the material.

In order to validate obtained WAXS results, the DSC studies were performed using a Netzsch Differential Scanning Calorimeter, model DSC 200, in a nitrogen atmosphere. The samples were heated to $200{ }^{\circ} \mathrm{C}$ (at a heating rate of $10{ }^{\circ} \mathrm{C} / \mathrm{min}$ ) and kept at this temperature for $2 \mathrm{~min}$. Then, the samples were quenched to $40{ }^{\circ} \mathrm{C}$ at the rate of $5{ }^{\circ} \mathrm{C} / \mathrm{min}$ (using nitrogen flow). The cycle was repeated twice and the data from the second cycle were interpreted.

\section{Polarizing optical microscope-in situ observations of crystallization}

In the POM investigations the polarized optical microscope Axio Lab A1 (Zeiss, Germany), the ToupView camera and Linkam CSS 450 shear-hot stage (Linkam Scientific Instruments, UK) were used. The research was divided into three main parts:

I) observations of crystallization kinetics, II) the temperature dependence of shear nucleating ability and III) the formation of $\beta$ phase of iPP.

In the first part of the research, in order to analyze the morphology and crystallization kinetics, shearing protocol "A" was used (Fig. 2). Polypropylene films were heated with $30^{\circ} \mathrm{C} / \mathrm{min}$ gradient to $200^{\circ} \mathrm{C}$. The material was kept at the temperature $200{ }^{\circ} \mathrm{C}$ for $300 \mathrm{~s}$, to reduce the "crystalline 


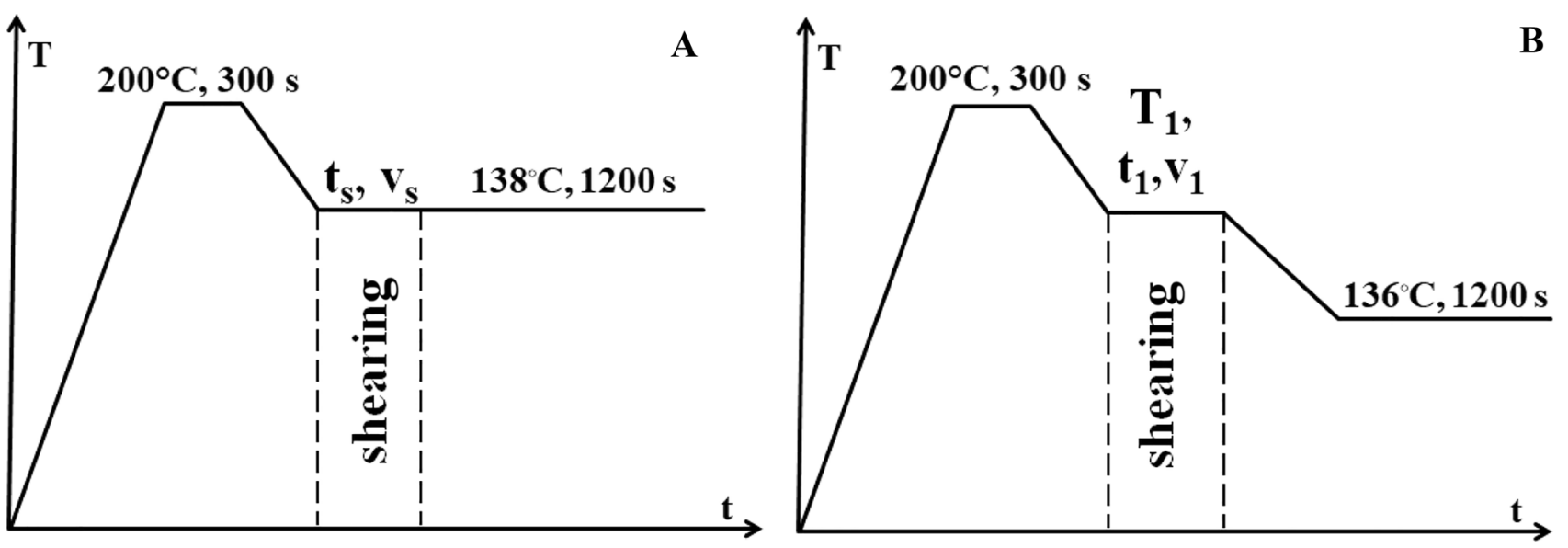

Fig. 2 The temperature and shearing protocols used: A - for the analysis of differences in spherulites structures morphology and spherulites diameters, $\mathbf{B}$ - for the observation of crystallization regimes

memory" phenomenon. Afterwards, the melt was cooled with $30^{\circ} \mathrm{C} / \mathrm{min}$ gradient to the temperature $136^{\circ} \mathrm{C}$. Subsequently, after the regulation of the gap between plates to $250 \mu \mathrm{m}$, the melt was treated with use of shear forces, which had specified shear rate $\mathrm{v}_{\mathrm{s}}$ and shear time $\mathrm{t}_{\mathrm{s}}$ (Table 1). The crystallization process was observed for $20 \mathrm{~min}$ with use of the POM technique.

In the second and third part of this study the shearing protocol "B" presented in Fig. 2 was used. After the melting in a temperature of $200^{\circ} \mathrm{C}$ for $300 \mathrm{~s}$, the material was cooled with $30^{\circ} \mathrm{C} / \mathrm{min}$ gradient to the temperature $\mathrm{T}_{1}$. The used temperature $\mathrm{T}_{1}$ values were: $154,150,145,140,138$ and $136^{\circ} \mathrm{C}$. Then the gap between plates was adjusted to $250 \mu \mathrm{m}$ and the shear treatment was carried out (Table 1). After shear treatment the melt was cooled to $138^{\circ} \mathrm{C}$ and the isothermal crystallization of iPP was observed with the use of a POM microscope.

Furthermore, the observations of selective-melting of spherulites during heating have been carried out. The $\beta$ phase of iPP melts in a temperature of about $150^{\circ} \mathrm{C}$, and the $\alpha$ iPP melts in a higher value of temperature, about $160-170^{\circ} \mathrm{C}$. The samples have been sheared with values of shear rate and shear time presented in Table 1 . The order of operation was analogue, like in "B" shearing protocol, but after melting of iPP samples the behavior of spherulites in increasing temperature was observed. The crystallization of

Table 1 The shear and temperature parameters applied in current insitu, hot-shear stage POM investigations

\begin{tabular}{llll}
\hline $\begin{array}{l}\text { Shearing pro- } \\
\text { tocol }\end{array}$ & $\begin{array}{l}\mathrm{T}_{\mathrm{s}} \\
{\left[{ }^{\circ} \mathrm{C}\right]}\end{array}$ & $\begin{array}{l}\mathrm{v}_{\mathrm{s}} \\
{\left[\mathrm{s}^{-1}\right]}\end{array}$ & $\begin{array}{l}\mathrm{t}_{\mathrm{s}} \\
{[\mathrm{s}]}\end{array}$ \\
\hline $\mathrm{A}$ & 138 & 1,$5 ; 3,0 ; 4,5$ & $10 ; 30$ \\
$\mathrm{~B}$ & $136,138,140,145$, & 1,$5 ; 4,5$ & 10 \\
& 150,154 & & \\
\hline
\end{tabular}

iPP samples in quiescent conditions (without shear treatment) was executed.

\section{Interpretation of POM micrographs}

Based on POM photographs, it was possible to set the very important parameter of crystalline structures growth. The spherulites growth rate $\left(\mu \mathrm{m} \cdot \mathrm{s}^{-1}\right)$, which defines the spherulites diameter increase during one second, was calculated on base of spherulites diameters measurements after $20 \mathrm{~min}$ of isothermal crystallization.

\section{Results and discussion}

\section{The polymorphic structures of isotactic polypropylene}

Figure 3 shows the WAXS curve prepared for iPP. It can be observed that there are a few significant differences in the supermolecular structure of examined polypropylenes. Only for the PP2 has the diffraction maximum at $2 \theta$ degree $16^{\circ}$ been noticed, which suggests the $\beta$ form of iPP presence in the material. It is an interesting phenomenon that the compression molding of that polymer induces the pseudohexagonal form nucleation. In the research of Garbarczyk and Paukszta [56] the formation of $\beta$-phase in compressed iPP has been analyzed with a presence of $\beta$-nucleating agents. It has been proved that the high pressure undermines the abilities of agents to nucleation. However, an intern slip between polymer layers (like in case of shearing model, when the fluid is divided into infinitely many and infinitely thin parallel layers) can probably induce a small amount of $\beta$-crystalls.

The amount of $\beta$-phase $(k)$ in the crystalline phase of polypropylene has been determined through use of the 

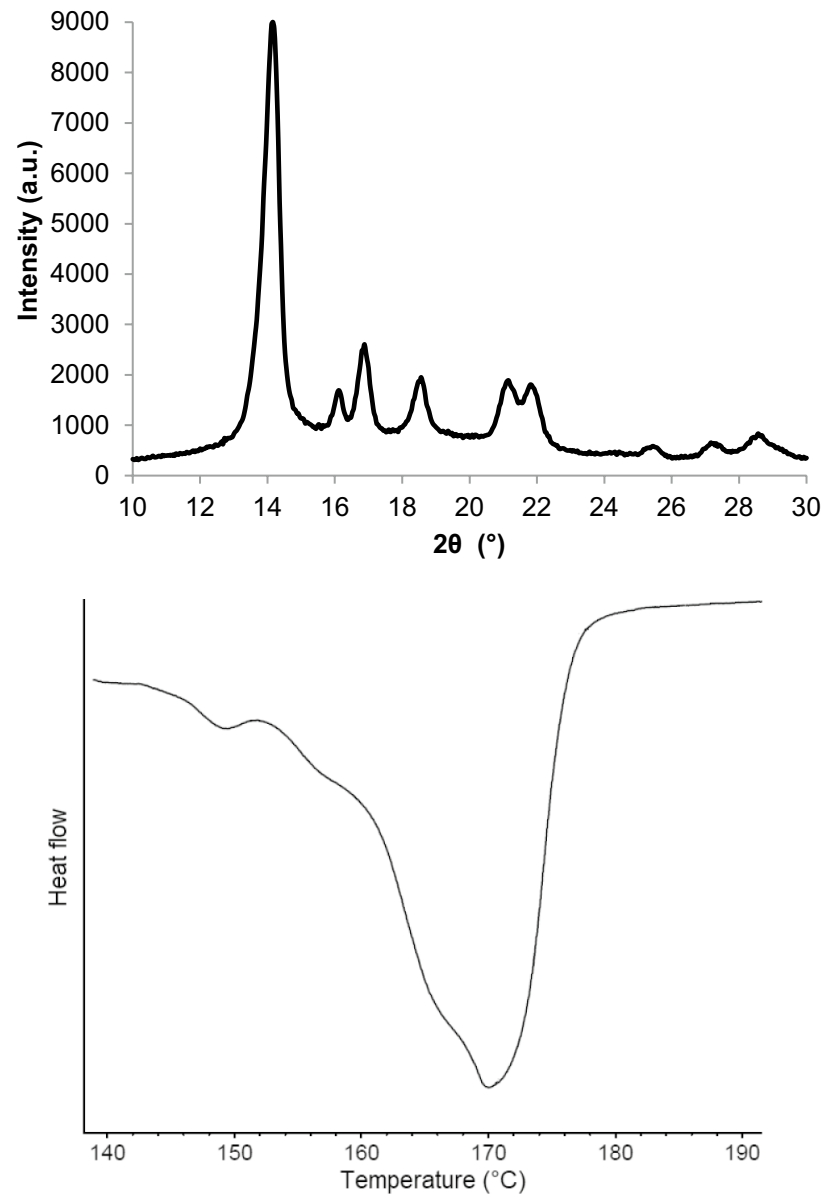

Fig. 3 The WAXS and DSC curves prepared for examined material

modified Turner-Jones equation [21], using performed WAXS results:

$k=\frac{P_{\beta 1}}{P_{\beta 1}+P_{\alpha 1}+P_{\alpha 2}+P_{\alpha 3}}$

where:

$P_{\beta 1}$ - area of diffraction maxima coming from (300) $\beta$-form plane;

$P_{\alpha l}$ - area of diffraction maxima coming from (110) $\alpha$-form plane;

$P_{\alpha 2}$ - area of diffraction maxima coming from (040) $\alpha$-form plane;

$P_{\alpha 3}$ - area of diffraction maxima coming from (130) $\alpha$-form plane;

and the calculated value of $\mathrm{k}$ was about 0,015 .

In Fig. 3 the results of the DSC analysis are presented. As can be seen, the low peak from $\beta$ iPP phase melting in the temperature $152^{\circ} \mathrm{C}$ in PP2 material can be observed, so the $\beta$-phase presence in the material has been confirmed.
Spherulites growth rate and crystallites morphology after shearing

Figure 4 shows values of the spherulites growth rate and density nucleation measured for iPP, crystallized in various shear conditions. It is known from the literature that the kinetics of spherulites growth closely depends on the shear rate. it can be observed that the higher the shear rate is, the higher the growth rate of spherulites.

As can be seen in Fig. 4, in the iPP sheared for $10 \mathrm{~s}$, a high increase of $G$ can be found, from about 0,036 to $0,055 \mu \mathrm{m} / \mathrm{s}$. However, in the melt sheared for $30 \mathrm{~s}$, the difference in the $\mathrm{G}$ parameter value between iPP samples crystallized in quiescent conditions and sheared samples was lower. Moreover, the sharp increase in growth rate was observed between melt crystallized in quiescent conditions and sheared with rate $1.5 \mathrm{~s}^{-1}$, where the further growth of shear rate does not affect the crystallization kinetic significantly. The same correlation may be observed in case of nucleation density. Shear flow through preordering of iPP chains affects simultaneouslythe formation of stable nucleis (primary nucleation) as well as crystallization kinetics (secondary nucleation and crystallites growth).

Considering the data shown in Fig. 4, it can be concluded that for iPP the increase of shear time decreases the influence of shear forces on crystallization kinetics as well as nucleation process. The shear stress affected too long, what perhaps over-extends the polymer chains, which impedes the re-arrangement after cessation of shear forces and stable nucleis formation. In the research of Somani et al. [57] it has been concluded that during the treatment of melt with low values of shear rate, only smart parts of chains are able to orientate and crystallize. In the short-time treatment with high shear rate, the segments of macromolecules are oriented for too short a time for create a stable nucleis. The macromolecules orientation is induced more effectively in short-duration shear treatment at a high shear rate than that in long-time shear with low shear rate.

Except for the differences in crystallization kinetics, various morphology in shear-oriented crystallites may be observed. Figure 5a, b show the iPP samples, crystallized in quiescent conditions and after shear treatment.

As can be seen in Fig. 5, the iPP material shows a tendency to the creation of fibril-liked structures, also called fibrils crystallites in the samples sheared during $10 \mathrm{~s}$ and $30 \mathrm{~s}$, with shear rates only $4,5 \mathrm{~s}^{-1}$. Pantani et al. [46, 58] considered the fibrilar morphology formation in sheared iPP melts. The conclusion was that above the concrete value of shear rate, the pre-formed crystallites can connect together into fibrilar structures as a result of flow. The critical shear rate value, presented in Pantani's work, was $\sim 0,46 \mathrm{~s}^{-1}$. Thus, in current research the critical value was exceeded and it may be concluded that the formation of fibrils depends 
Fig. 4 The morphology of crystallized iPP: a the growth of spherulites and fibrils in sheared iPP, $b$ the spherulites growth rate and nucleation density measured for different shear rates and shearing time
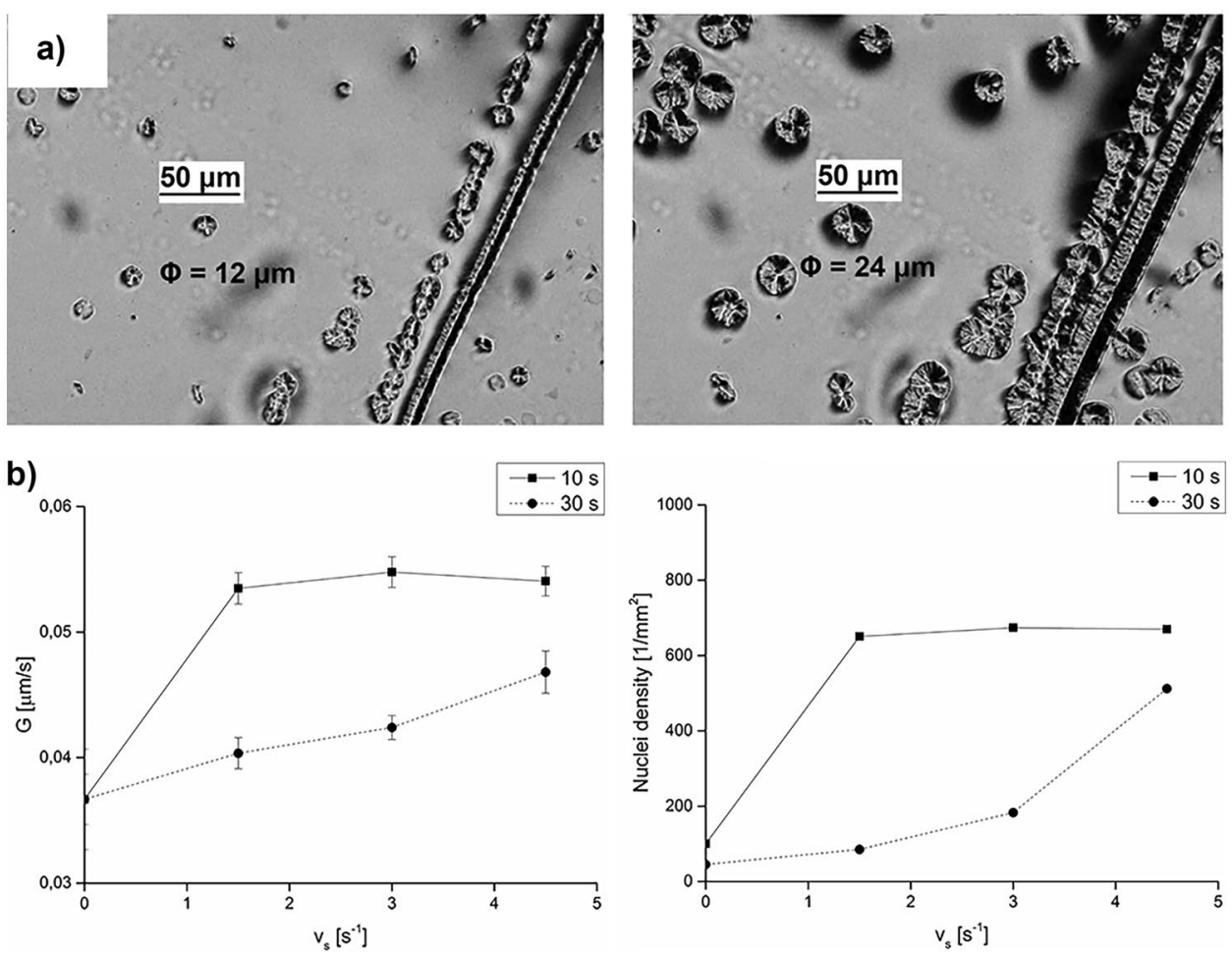

not only on chains ordering through shear strain but also on the molecular weight of the polypropylene used as well as the chains length.

\section{The temperature regimes in case of shear-induced crystallization}

The polymer chains, oriented by shear flow, after cessation of shear can return into the amorphous melt through the shear-stress relaxation phenomena or may create the energetically-stable nuclei. Figure 6 shows the spherulites growth rate as a function of the shearing temperature. As can be seen, there can be found an optimal, from the point of view of spherulites diameters growth, temperature value $\left(138^{\circ} \mathrm{C}\right)$. It is connected with the occurrence of crystallization process regimes.

In the research of Huo et al. [43] a conclusion was made that in the temperature $142^{\circ} \mathrm{C}$ and higher, the abilities of

Fig. 5 POM micrographs taken after $20 \mathrm{~min}$. of isothermal crystallization at $138{ }^{\circ} \mathrm{C}$ : $\mathbf{a}$ in quiescent conditions; $\mathbf{b}$ after shearing $\left(\mathrm{v}_{\mathrm{s}}=4,5 \mathrm{~s}^{-1}, \mathrm{t}_{\mathrm{s}}=10 \mathrm{~s}\right)$
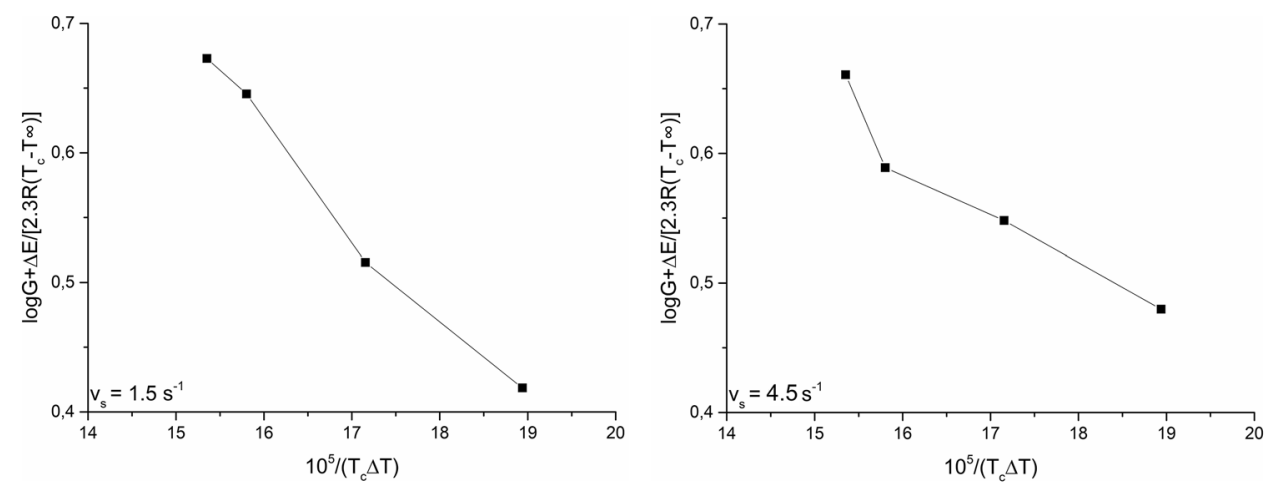
undercooling $\left(\mathrm{T}_{\mathrm{m}}^{0} \mathrm{~T}_{\mathrm{c}}\right), \mathrm{T}_{\infty}=231,2 \mathrm{~K}$ and $\mathrm{T}_{\mathrm{m}}^{0}=458,2 \mathrm{~K}$. It may be observed that the transition temperatures between various regimes are constant and depend only on the heat parameters and also do not depend on shear treatment. Thus, it may be concluded that the secondary nucleation process plays a greater role in overall crystallization kinetics than the primary, shear-induced nucleation.

\section{The presence of $\alpha$ and $\beta$ iPP phase in sheared samples}

To verify what kind of the crystallographic form of spherulites has been created through shear treatment, the method of selective-melting of iPP crystallites was carried out [60]. Observation of the melting of shear-induced spherulites in slow-increasing temperature allows to comment on the $\beta$ and $\alpha$ form of iPP crystallites. After heating the crystallized
iPP film to the lower temperature value of $150-158^{\circ} \mathrm{C}$, the disappearance of $\beta$-spherulites can be observed. Spherulites created form $\alpha$ iPP phase melts until at the higher temperatures, between $160-170^{\circ} \mathrm{C}$. Figure $8 \mathrm{a}-\mathrm{c}$ shows the spherulites behavior during heating of crystallized iPP films.

As can be seen in Fig. 8 and in Table 2, the melting of spherulites in the lower temperature of $158^{\circ} \mathrm{C}$ has been noticed only in the case of the melting of iPP samples crystallized after shear treatment.

Firstly, it should be emphasized that the shear forces induce a $\beta$ phase of iPP formation [35, 38]. However, only for the samples sheared in the lower value of temperature $T_{s}$, $138^{\circ} \mathrm{C}$, can the occurrence of $\beta$ phase of iPP be noticed. In the research Huo et al. a conclusion can be found that above the concrete temperature value, the relaxation phenomena dominates over the shear-induced nucleation [43]. Thus, it can be said that the shear forces' ability for nucleation
Fig. 6 Spherulites growth rate (G) after shear treatment in different shear temperature $\left(\mathrm{T}_{\mathrm{s}}\right)$ : a shear rate $1,5 \mathrm{~s}^{-1}$, b shear rate $4,5 \mathrm{~s}^{-1}$
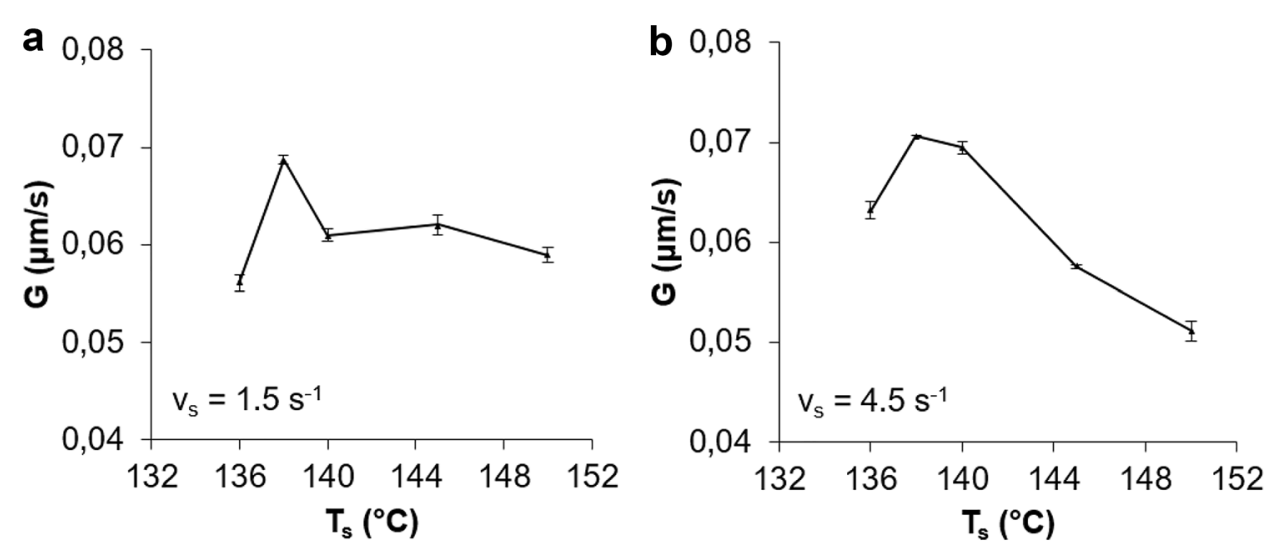

Fig. 7 The plots $\log +\Delta \mathrm{E}(2.3$ $\mathrm{R}\left(\mathrm{T}_{\mathrm{c}}-\mathrm{T}_{\infty}\right)$ versus $1 /\left(\mathrm{T}_{\mathrm{c}} \Delta \mathrm{T}\right)$ determined for iPP sheared with shear rate appropriate $1.5 \mathrm{~s}^{-1}$ and $4.5 \mathrm{~s}^{-1}$
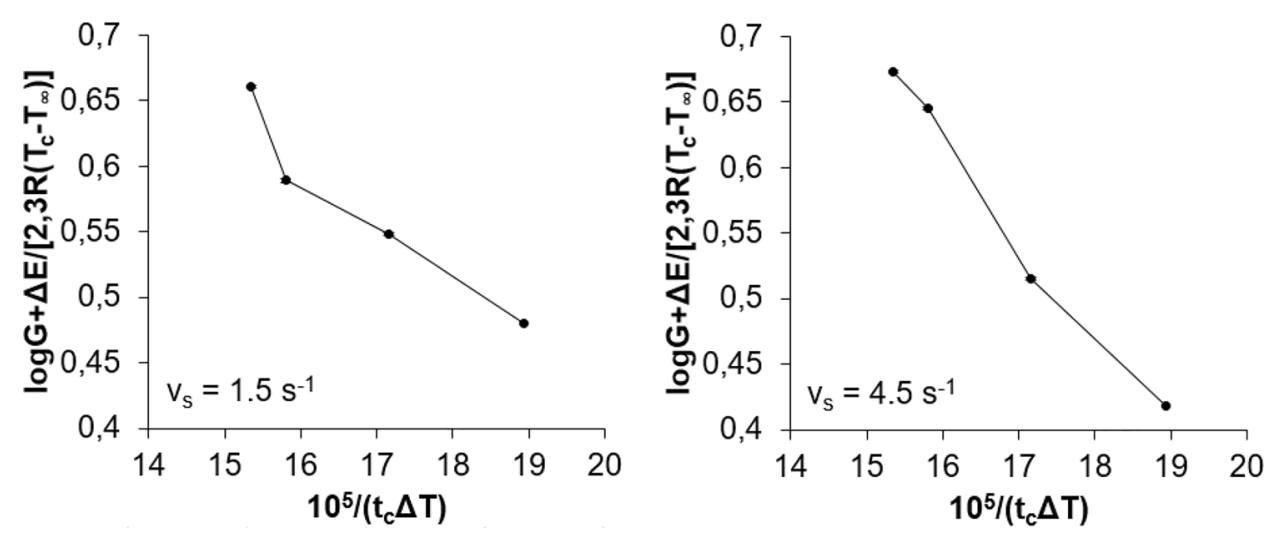

Fig. 8 The microscope images made during slow melting of shear-treated samples. Pictures a-c show iPP sheared in $138^{\circ} \mathrm{C}$ $\left(\mathrm{v}_{\mathrm{s}}=4,5, \mathrm{t}_{\mathrm{s}}=10 \mathrm{~s}\right)$
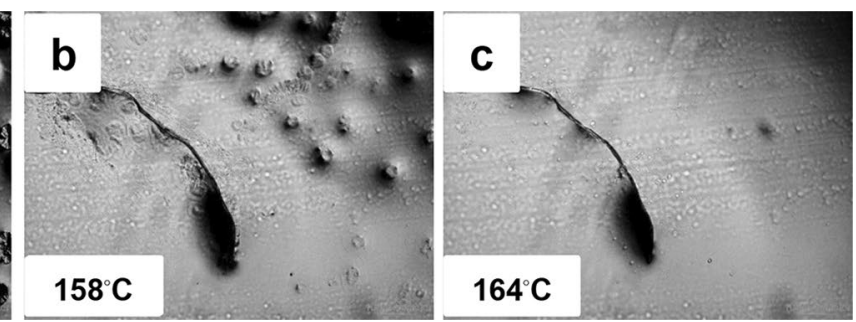
Table 2 Crystallographic forms of iPP observed in samples crystallized in different conditions

\begin{tabular}{llll}
\hline Shearing conditions & & $\begin{array}{l}\text { Crystallographic form of iPP } \\
\text { present in shear-treated melt }\end{array}$ \\
\hline $\mathbf{T}_{\mathbf{s}}$ & $\mathbf{v}_{\mathbf{s}}$ & $\mathbf{t}_{\mathbf{s}}$ & \\
{$\left[{ }^{\circ} \mathrm{C}\right]$} & {$\left[\mathrm{s}^{-1}\right]$} & {$[\mathrm{s}]$} & \\
154 & 4,5 & 10 & $\alpha$ \\
& & 30 & $\alpha$ \\
138 & 4,5 & 10 & $\alpha$ and $\beta$ \\
& & 30 & $\alpha$ and $\beta$ \\
\hline
\end{tabular}

decreases with increase of temperature. However, in our research only the growth of $\alpha$ spherulites in melt sheared in temperature $154^{\circ} \mathrm{C}$ can be observed. It should be highlighted why, in the higher temperature of shearing only, the $\alpha$ iPP form can be induced by shear forces. Moreover, the nucleis of $\beta$ crystals created in the temperature higher than the value where the $\beta$-phase may occur, decompose immediately back to an amorphous phase or they reorganize on the line of $\beta \rightarrow \alpha$ transition. The next possible reason for the described phenomenon is that in higher temperatures, wherein the nucleating abilities of shear forces are weaker, only the more energy-stable, monoclinic $\alpha$ form can be created. The shear forces in higher shear temperatures cannot make enough influence for chains, which is necessary for reorganization of them and creation of $\beta$ crystals.

\section{Conclusions}

In this research, the shear-induced crystallization phenomenon was studied. It was focused on the kinetics crystallization of iPP as well as crystallites morphology and the occurrence of $\beta$-iPP. The formation of row nucleis and, in consequence, the fibrillar crystallites may be noticed only after shear treatment with shear rate over concrete, critical value (in current study higher than in the literature data, presented earlier).

The key parameter determining the shear-induced crystallization is a temperature value during shearing. It determines the crystallites morphology as well as crystallization kinetics. The shear rate and shearing time should not be neglected but from the viewpoint of the three crystallization regimes, the secondary homonucleation process is more important than the primary, shear-induced nucleation.

The influence of shear forces on crystallization kinetics and crystallites morphology (e.g., fibrils formation) is closely dependent on polypropylene type and processing characteristic. The shear forces may induce the $\beta$-iPP formation only in the appropriate temperature range. For samples sheared in the temperature higher than the melting temperature of $\beta$ iPP value, the shear-induced $\beta$-crystallization cannot be observed in contrast to the samples sheared in the lower temperature $\left(138^{\circ} \mathrm{C}\right)$. In higher temperatures, the abilities of shear forces to induce crystallization are weaker, and their abilities to creation $\beta$ iPP nucleis practically do not occur.

Acknowledgements Authors give thanks to Mrs. Katarzyna Budaj. This work was supported by the Polish Ministry of Education and Science.

Open Access This article is licensed under a Creative Commons Attribution 4.0 International License, which permits use, sharing, adaptation, distribution and reproduction in any medium or format, as long as you give appropriate credit to the original author(s) and the source, provide a link to the Creative Commons licence, and indicate if changes were made. The images or other third party material in this article are included in the article's Creative Commons licence, unless indicated otherwise in a credit line to the material. If material is not included in the article's Creative Commons licence and your intended use is not permitted by statutory regulation or exceeds the permitted use, you will need to obtain permission directly from the copyright holder. To view a copy of this licence, visit http://creativecommons.org/licenses/by/4.0/.

\section{References}

1. Borysiak S (2015) The thermo-oxidative stability and flammability of wood/polypropylene composites. J Therm Anal Calorim 119(3):1955-1962

2. Corradini P (2004) The discovery of isotactic polypropylene and its impact on pure and applied science. J Polym Sci A Polym Chem 42(3):391-395

3. Varga J (1992) Supermolecular structure of isotactic polypropylene. J Mater Sci 27(10):2557-2579

4. Kosciuszko A, Marciniak D, Sykutera D (2021) Post-processing time dependence of shrinkage and mechanical properties of injection-molded polypropylene. Materials 14(1)

5. Coppola B, Di Maio L, Incarnato L, Tulliani JM (2021) Preparation and Characterization of Polypropylene/Carbon Nanotubes (PP/CNTs) nanocomposites as potential strain gauges for structural health monitoring. Nanomaterials 10(4)

6. Nobe R, Qiu JH, Kudo M, Zhang GH (2020) Morphology and mechanical investigation of microcellular injection molded carbon fiber reinforced polypropylene composite foams. Polym Eng Sci 60(7):1507-1519

7. Ma QY, Hu MF, Yuan Y, Pan YK, Chen MQ, Zhang YY, Long DH (2020) Colloidal dispersion of Nb2O5/reduced graphene oxide nanocomposites as functional coating layer for polysulfide shuttle suppression and lithium anode protection of Li-S battery. J Colloid Interface Sci 566:11-20

8. Xu S, Li SY, Zhang M, Zeng HY, Wu K, Tian XY, Chen CR, Pan Y (2020) Fabrication of green alginate-based and layered double hydroxides flame retardant for enhancing the fire retardancy properties of polypropylene. Carbohydr Polyme 234

9. Tienne LGP, Cordeiro SB, Brito EB, Marques MDV (2020) Microcrystalline cellulose treated by steam explosion and used for thermo-mechanical improvement of polypropylene. J Compos Mater 54(24):3611-3624

10. Zhang H, Zhen Q, Cui JQ, Liu RT, Zhang YF, Qian XM, Liu Y (2020) Groove-shaped polypropylene/polyester micro/nanofibrous nonwoven with enhanced oil wetting capability for high oil/water separation. Polymer 193 
11. Agarwal J, Mohanty S, Nayak SK (2020) Valorization of pineapple peel waste and sisal fiber: Study of cellulose nanocrystals on polypropylene nanocomposites. J Appl Polym Sci 137(42)

12. Al-Shalchy SI, Shabeeb KM, Hasan AM, Hasan RF (2020) Mechanical Properties of Polyvinyl Chloride and Polypropylene Hybrid Polymeric Nanocomposites for Structural Applications. Int J Nanoelectron Mater 13(2):249-262

13. Reynolds N, Awang-Ngah S, Williams G, Hughes DJ (2020) Direct Processing of Structural Thermoplastic Composites Using Rapid Isothermal Stamp Forming. Appl Compos Mater 27(1-2):107-115

14. Vigneshwaran S, Sundarakannan R, John KM, Johnson RJD, Prasath KA, Ajith S, Arumugaprabu V, Uthayakumar M (2020) Recent advancement in the natural fiber polymer composites: A comprehensive review. J Clean Prod 277

15. Wang SH, Li JS, Wang WJ, Wang, XG Li HF, Sun J, Fei B, Gu XY, Zhang S (2021) Silicone filled halloysite nanotubes for polypropylene composites: Flame retardancy, smoke suppression and mechanical property. Compos Part A Appl Sci Manuf 140

16. Bicy K, Paul AP, Kalarikkal N, Stephen AM, Geethamma VG, Rouxel D, Thomas S (2021) Effects of nanofillers on morphology and surface wetting of microporous polypropylene composite membranes. Mater Chem Phys 257

17. Zhang MC, Guo BH, Xu J (2017) A Review on Polymer Crystallization Theories. Crystals 7(1):37

18. Phillips PJ (1993) EFFECTS OF CHEMICAL MICROSTRUCTU RE ON REGIMES IN POLYMER CRYSTALLIZATION. Polym Crystallization 405:301-311

19. Hoffman JD, Miller RL (1997) Kinetics of crystallization from the melt and chain folding in polyethylene fractions revisited: Theory and experiment. Polymer 38(13):3151-3212

20. Pawlak A, Krajenta J, Galeski A (2017) The Crystallization of Polypropylene with Reduced Density of Entanglements. J Polym Sci B Polym Phys 55(9):748-756

21. Jones AT, Aizlewood JM, Beckett DR (1964) CRYSTALLINE FORMS OF ISOTACTIC POLYPROPYLENE. Makromolekulare Chemie 75:134-158

22. Garbarczyk J, Paukszta D (1985) Influence of additives on the structure and properties of polymers .3. Study of beta- alphatransition in isotactic polypropylene at various temperatures and times of heating. Colloid Polym Sci 263(12):985-990

23. Varga J (1995) Crystallization, melting and supermolecular structure of isotactic polypropylene. In: Karger-Kocsis J (ed) Polypropylene: Structure, Blends and Composites, Voll. Structure and Morphology Chapman \& Hall, London, pp 56-115

24. Garbarczyk J, Sterzynski T, Paukszta D (1989) Influence of additives on the structure and properties of polymers .4. Study of phase-transition in isotactic polypropylene by synchrotron radiation. Polym Commun 30(5):153-157

25. Garbarczyk J, Paukszta D (1981) Influence of additives on the structure and properties of polymers .2. Polymorphic transitions of isotactic polypropylene caused by aminosulpfur compounds. Polymer 22(4):562-564

26. Piccarolo S (1992) Morphological-changes in isotactic polypropylene as a function of cooling rate. J Macromol Sci Phys B31(4):501-511

27. Fischer C, Drummer D (2016) Crystallization and mechanical properties of polypropylene under processing-relevant cooling conditions with respect to isothermal holding time. Int J Polym Sci 11

28. Romankiewicz A, Sterzynski T, Brostow W (2004) Structural characterization of alpha- and beta-nucleated isotactic polypropylene. Polym Int 53(12):2086-2091

29. Lin Y, Chen HB, Chan CM, Wu JS (2011) Nucleating effect of calcium stearate coated $\mathrm{CaCO} 3$ nanoparticles on polypropylene. J Colloid Interface Sci 354(2):570-576
30. Barczewski M, Matykiewicz D, Hoffmann B (2017) Effect of quinacridone pigments on properties and morphology of injection molded isotactic polypropylene. Int J Polym Sci 8

31. Borysiak S, Doczekalska B (2006) Influence of chemical modification of wood on the crystallisation of polypropylene. Holz Als Roh-Und Werkstoff 64(6):451-454

32. Jerschow P, JaneschitzKriegl H (1997) The role of long molecules and nucleating agents in shear induced crystallization of isotactic polypropylenes. Int Polym Process 12(1):72-77

33. Janeschitz-Kriegl H (2017) A Recollection with Respect to Flow Induced Crystallization in Polymer Melt Processing. Int Polym Process 32(2):227-236

34. Lotz B (1997) The structure and morphology of crystalline polymers. Nucl Instrum Methods Phys Res B 131(1-4):13-21

35. Garbarczyk J, Borysiak S (2004) Polypropylene - Cellulose fibres composites. Part I. Influence of conditions of extrusion and injection processes on the structure of polypropylene matrix. Polimery 49(7-8):541-546

36. Kowalska B (2007) Study on crystallization of polymers during the injection molding. Polimery 52(2):83-87

37. Yang B, Lin JZ, Xia R, Su LF, Miao JB, Qian JS, Chen P, Liu JW, Deng SQ (2014) Correlation Between Solidification Behavior and Melt Crystallization Kinetics of Isotactic Polypropylene (iPP) during Injection Molding. J Macromol Sci Phys J Macromol Sci B 53(3):462-473

38. Paukszta D, Szostak M, Bednarek WH, Maciejczak W (2019) The structure of isotactic polypropylene in composites filled with lignocellulosic material. J Nat Fibers 16(4):471-483

39. Nogales A, Hsiao BS, Somani RH, Srinivas S, Tsou AH, BaltaCalleja FJ, Ezquerra TA (2001) Shear-induced crystallization of isotactic polypropylene with different molecular weight distributions: in situ small- and wide-angle X-ray scattering studies. Polymer 42(12):5247-5256

40. Somani RH, Yang L, Hsiao BS (2002) Precursors of primary nucleation induced by flow in isotactic polypropylene. Physica a-Statistical Mechanics and Its Applications 304(1-2):145-157

41. Koscher E, Fulchiron R (2002) Influence of shear on polypropylene crystallization: morphology development and kinetics. Polymer 43(25):6931-6942

42. Huo H, Jiang SC, An LJ, Feng JC (2004) Influence of shear on crystallization behavior of the beta phase in isotactic polypropylene with beta-nucleating agent. Macromolecules 37(7):2478-2483

43. Huo H, Meng YF, Li HF, Jiang SC, An LJ (2004) Influence of shear on polypropylene crystallization kinetics. Eur Phys J E 15(2):167-175

44. Zhang CG, Hu HQ, Wang DJ, Yan S, Han CC (2005) In situ optical microscope study of the shear-induced crystallization of isotactic polypropylene. Polymer 46(19):8157-8161

45. Patil N, Invigorito C, Gahleitner M, Rastogi S (2013) Influence of a particulate nucleating agent on the quiescent and flowinduced crystallization of isotactic polypropylene. Polymer 54(21):5883-5891

46. Pantani R, Nappo V, De Santis F, Titomanlio G (2014) Fibrillar Morphology in Shear-Induced Crystallization of Polypropylene. Macromol Mater Eng 299(12):1465-1473

47. Najafi N, Heuzey MC, Carreau P, Therriault D (2015) Quiescent and shear-induced crystallization of linear and branched polylactides. Rheologica Acta 54(9-10):831-845

48. De Santis F, Pantani R, Titomanlio G (2016) Effect of shear flow on spherulitic growth and nucleation rates of polypropylene. Polymer 90:102-110

49. Luo BJ, Li HF, Zhang WY, Zhou CB, Li JQ, Lu CH, He XH, Jiang SC (2017) Mechanistic insights into the shear effects on isotactic polypropylene crystallization containing beta-nucleating agent. Chinese J Polym Sci 35(5):672-680 
50. Dikovsky D, Marom G, Avila-Orta CA, Somani RH, Hsiao BS (2005) Shear-induced crystallization in isotactic polypropylene containing ultra-high molecular weight polyethylene oriented precursor domains. Polymer 46(9):3096-3104

51. Avila-Orta CA, Burger C, Somani R, Yang L, Marom G, MedellinRodriguez FJ, Hsiao BS (2005) Shear-induced crystallization of isotactic polypropylene within the oriented scaffold of noncrystalline ultrahigh molecular weight polyethylene. Polymer 46(20):8859-8871

52. Sun TC, Chen FH, Dong X, Zhou Y, Wang DJ, Han CC (2009) Shear-induced orientation in the crystallization of an isotactic polypropylene nanocomposite. Polymer 50(11):2465-2471

53. Fiorentino B, Fulchiron R, Duchet-Rumeau J, Bounor-Legare V, Majeste JC (2013) Controlled shear-induced molecular orientation and crystallization in polypropylene/talc microcomposites Effects of the talc nature. Polymer 54(11):2764-2775

54. Ma GQ, Li D, Sheng J (2015) Shear-induced crystallization in phase-separated blends of isotactic polypropylene with ethylene-propylene-diene terpolymer. Chinese J Polym Sci 33(11):1538-1549

55. Keum JK, Mao YM, Zuo F, Hsiao BS (2013) Flow-induced crystallization precursor structure in high molecular weight isotactic polypropylene (HMW-iPP)/low molecular weight linear low density polyethylene (LMW-LLDPE) binary blends. Polymer 54(4):1425-1431
56. Paukszta D, Garbarczyk J (2003) Crystallization of isotactic polypropylene with $\beta$-nucleating agents under elevated pressure. FIBRES \& TEXTILES in Eastern Europe 11(5 (44)):50-53

57. Somani RH, Yang L, Hsiao BS, Sun T, Pogodina NV, Lustiger A (2005) Shear-induced molecular orientation and crystallization in isotactic polypropylene: Effects of the deformation rate and strain. Macromolecules 38(4):1244-1255

58. Pantani R, Nappo V, De Santis F, Titomanlio G (2013) Fibrillar morphology formation in a sheared polypropylene melt, 29th International Conference of the Polymer-Processing-Society (PPS), Nuremberg, GERMANY, pp 76-79

59. Phillips AW, Bhatia A, Zhu PW, Edward G (2011) Shish Formation and Relaxation in Sheared Isotactic Polypropylene Containing Nucleating Particles. Macromolecules 44(9):3517-3528

60. Wang JY, Wang XH, Wang QJ, Xu C, Wang ZG (2018) Effect of Flowing Preformed Spherulites on Shear-Induced Melt Crystallization Behaviors of Isotactic Polypropylene. Macromolecules 51(5):1756-1768

Publisher's Note Springer Nature remains neutral with regard to jurisdictional claims in published maps and institutional affiliations. 